\title{
Seroprevalence of Echinococcus spp. and Toxocara spp. in Invasive Non-native American Mink
}

\author{
Marta Kołodziej-Sobocińska®i, ${ }^{1}$ Emília Dvorožňáková, ${ }^{2}$ Zuzana Hurníková, ${ }^{2}$ \\ Katarína Reiterová, ${ }^{2}$ and Andrzej Zalewski ${ }^{1}$ \\ ${ }^{1}$ Mammal Research Institute, Polish Academy of Sciences, Stoczek 1, 17-230 Białowieża, Poland \\ ${ }^{2}$ Institute of Parasitology, Slovak Academy of Sciences, Hlinkova 3, 04001 Kosice, Slovak Republic
}

\begin{abstract}
Invasive non-native species can become reservoirs of zoonotic pathogens and cause their spread during colonization, increasing the risk of zoonoses transmission to both wild hosts and humans. American mink (Neovison vison) are considered an important invasive mammal species responsible for carrying endoparasites. The aim of our study was to evaluate the role of feral American mink as a possible transmission vector of Echinococcus spp. and Toxocara spp. in wildlife. We analysed the frequency of American mink exposure to both parasites, the spatial distribution in Poland, and the variability over time on the basis of specific antibody presence using ELISA and Western blot. Alimentary tract analyses revealed that American mink do not serve as definitive hosts for these parasites. Altogether, 1100 American mink were examined. The average seropositivity for American mink was $14.2 \%$ for echinococcosis and $21.7 \%$ for toxocarosis; dualseropositivity was detected in only $6.0 \%$. Seroprevalence of both parasites differed between study sites and significantly increased over time in Toxocara spp. Thus, our study revealed that free-living American mink are exposed to parasites and likely to be involved in the maintenance of both Echinococcus spp. and Toxocara spp. in the wild as paratenic hosts.
\end{abstract}

Keywords: Invasive species, Seroprevalence, Zoonoses, Paratenic host, Echinococcosis, Toxocarosis

\section{INTRODUCTION}

Invasive non-native species are among the greatest threats to biodiversity, often causing a decrease in native species number and density in ecosystems (Vitousek et al. 1996). Among many others, one of the negative impacts of invasive species on ecosystems is their role as additional transmission vectors or reservoirs of native parasites and pathogens. Raccoon dogs (Nyctereutes procyonoides),

Published online: January 27, 2020

Correspondence to: Marta Kołodziej-Sobocińska, e-mail: mksobocinska@ibs.bialowieza.pl
American mink (Neovison vison), and raccoons (Procyon lotor), for instance, may be involved in the maintenance and transmission of many diseases across Europe, including those with zoonotic potential such as Trichinella spp., Alaria spp., Echinococcus multilocularis, and Toxocara spp. (Duscher et al. 2017; Hurníková et al. 2016; Laurimaa et al. 2016). The transmission rate of pathogens may be enhanced when introduced non-native invasive species reach high densities in newly colonized ecosystems (Kelly et al. 2009; Strauss et al. 2012; Carolus et al. 2019). Likewise, this increases the risk of disease occurrence in wild native hosts, 
domestic animals, and potentially humans (Carolus et al. 2019).

Pathogens like Echinococcus spp. and Toxocara spp. are important zoonotic agents with worldwide distributions (Jorgensen et al. 2008; Kern et al. 2003; Nahorski et al. 2013; Overgaauw and Nederland 1997). Alveolar echinococcosis (AE) occurs in at least 42 countries in the northern hemisphere (Kern et al. 2003; Nahorski et al. 2013). The larval form of E. multilocularis is the causative agent of $\mathrm{AE}$ in humans. Transmission of $\mathrm{AE}-\mathrm{a}$ lifethreatening helminthic zoonosis-to humans occurs when tapeworm eggs are accidentally ingested. Then, larvae settle in the liver and proliferate, and can also metastasize to more distant organs like the brain. The fatality rate for untreated human $\mathrm{AE}$ exceeded $90 \%$ within 10 years (Kern et al. 2003). European cases of AE have been registered since 1982 (Kern et al. 2003). In Poland, in particular, a total of 121 cases of AE have been confirmed (Nahorski et al. 2013), which puts Poland in the fourth place among all European counties. In neighbouring countries, like Germany, Slovakia, and the Czech Republic, AE is also a serious epidemiological problem (Jorgensen et al. 2008; Antolová et al. 2014; Kolarova et al. 2015). Knowledge about the reservoir of AE in wildlife focuses mainly on red fox (Vulpes vulpes) infection (Bagrade et al. 2016; Karamon et al. 2014; Miller et al. 2016; Umhang et al. 2016). Thus, it is thought that human $\mathrm{AE}$ is mainly present in areas with a large prevalence of infected red foxes (Nahorski et al. 2013; Schweiger et al. 2007). Nematode parasites of the genus Toxocara also cause severe diseases in humans (Chen et al. 2018), as people can acquire infection by, among other methods, ingestion of embryonated eggs present in contaminated soil or food. Toxocara spp. larvae migrate to various body organs, such as the liver, heart, lungs, kidneys, brain, muscles, or eyes, which causes a broad range of clinical symptoms.

Both echinococcosis and toxocarosis can be diagnosed with ELISA and Western blot. The use of serological data to study infection in wildlife is widely accepted (Fillaux and Magnaval 2013; Lassen et al. 2016; Pagnozzi et al. 2016). Seroprevalence studies of infected wild animals can be a good, easy, and cheap way to determine the occurrence of these zoonotic parasites in the environment. Serological methods offer a sensitive and relatively specific alternative to necropsies or digestion methods. The usefulness of both ELISA and Western blot was confirmed, for example, in $T$. canis and T. leonina diagnoses in experimentally infected paratenic hosts (Klockiewicz et al. 2019a). No false-posi- tive/false-negative results were stated in this study. In cases when blood samples are not available, muscle juice acts as the equivalent to serum for the detection of specific antibodies for E. multilocularis (Gottsteina et al. 2014) or Trichinella spiralis (Beck et al. 2005; Møller et al. 2005; Nöckler et al. 2005). An advantage of using muscle juice includes the long-term storage of samples collected for epidemiological studies, and it can also be a good alternative to testing samples from wild animals.

Knowledge about the presence of Echinococcus spp. and Toxocara spp. in wildlife is still sparse, and there is a need to supplement it with new data about possible reservoir hosts, sites of occurrence, and the importance of introduced species in the maintenance of these parasites in the environment. The prevalence of echinococcosis has mainly been studied in the red fox, and in Poland the highest proportion of infected individuals has been recorded in eastern regions (Karamon et al. 2014). However, other predators, including invasive non-native species, may participate in maintaining high abundances of the parasite in wildlife, e.g. the raccoon dog (Bagrade et al. 2016; Machnicka-Rowińska et al. 2002). Carnivorous mammals are hosts for both Echinococcus spp. and Toxocara spp. parasites (Bagrade et al. 2016; Holland 2017). Definitive hosts, such as red foxes, raccoon dogs, and wolves, shed parasite eggs into the environment and are important vectors in disease transmission, not only to other wild hosts, but also to humans who may accidentally ingest invasive forms of the parasites. Intermediate and/or paratenic hosts allow both parasites to complete their life cycles because larval forms settled in these hosts' tissues are the source of infection for definitive hosts- the carnivores preying upon them (Eckert and Deplazes 2004). Thus, intermediate and paratenic hosts, such as rodents and smaller predators, may enhance the probability of disease transmission (Wobeser 2006). Therefore, understanding parasitic zoonoses also requires data on the invasive mammal species' infection status, because these species may serve as hosts for parasites with zoonotic potential.

The American mink has been recognized as one of the most invasive alien mammal species and has significant impacts on ecosystems, reducing the number of native birds and mammals (Nentwig et al. 2010; Niemczynowicz et al. 2017; Brzeziński et al. 2020). The species originates from North America and has been introduced to many countries on three continents, mainly via breeding farms for fur production (Bonesi and Palazon 2007). In Europe, the American mink was introduced in the 1930s and has 
colonized 28 countries (Bonesi and Palazon 2007). In Poland, the feral population established itself in the early 1980 s and over the next 40 years colonized nearly the entire country except the mountains and uplands of south-eastern Poland (Zalewski et al. 2010; Brzeziński et al. 2019). In colonized areas, American mink population levels reach densities as high as 10-12 individuals per $10 \mathrm{~km}$ of river (Bartoszewicz and Zalewski 2003; Brzeziński et al. 2019). The species is a medium-sized mustelid and is a highly adaptive, opportunistic, semi-aquatic predator, inhabiting a variety of riparian habitats (Kauhala 1996; Sidorovich 2000; Brzeziński et al. 2018b; Zalewski et al. 2009). This wide range of occupied habitat is related to the species' generalist diet composition; American mink hunt varied prey, including both aquatic (mainly crayfish, fish, and frogs) and terrestrial (birds and rodents) species (Jędrzejewska et al. 2001; Zalewski and Bartoszewicz 2012). Dietary composition varies greatly between seasons and localities and has also changed over the period of American mink invasion (Jędrzejewska et al. 2001; Bartoszewicz and Zalewski 2003; Sidorovich et al. 2010; Brzeziński et al. 2018a). The carnivore typically lives no more than 6 years, but the mortality rate is high, especially in subadult mink (Bonesi et al. 2006). American mink may be killed and eaten by many larger predators, including dogs (Canis lupus familiaris) and wild carnivores like the Eurasian lynx (Lynx lynx), red fox, and wolf (Canis lupus) (Bryan et al. 2006; Errington 1937; Odden et al. 2006; Sepúlveda et al. 2014).

Data on the number of endoparasite species and infection rates in introduced ranges of American mink have up until recently been limited (Shimalov and Shimalov 2001a; Torres et al. 2003, 2008). Recent data from Poland have shown that newly established populations have much lower endoparasite abundances than older populations, but that these abundances increased within a relatively short period of approximately 20 years (Kołodziej-Sobocińska et al. 2018). On this basis, it can be assumed that in new territories where populations were established, the American mink potentially enhances risk of zoonotic transmission to humans. This was recently proven by our detection of three Trichinella species (T. spiralis, T. britovi, and $T$. pseudospiralis) in the American mink in its introduced range in Poland (Hurníková et al. 2016). Neither Echinococcus spp. nor Toxocara spp. infection (adult parasites and/or eggs) have been confirmed in American mink (Kołodziej-Sobocińska et al. 2018; Martínez-Rondán et al. 2017; Shimalov and Shimalov 2001a; Torres et al. 2003,
2008). In addition, the sole published experimental study found that after oral inoculation with Echinococcus multilocularis protoscoleces, no adult tapeworms were recovered from American mink intestines, and the authors concluded that American mink cannot serve as a definitive host for $E$. multilocularis (Ooi et al. 1992). Moreover, a recent experimental study done on farm American mink confirmed that this species may serve as a paratenic host for Toxocara canis and Toxascaris leonina (Klockiewicz et al. 2019a). Thus, American mink should be further investigated to receive more data about their involvement in maintaining zoonotic parasites in the environment, though it can be assumed that this species serves as a paratenic host for both parasites.

The aim of our study was to evaluate the frequency of American mink exposure to two zoonotic parasitesEchinococcus spp. and Toxocara spp.--and determine the role of this invasive species in the maintenance of both parasites in the environment. In this study, we analysed seroprevalence by detecting specific anti-Echinococcus spp. and anti-Toxocara spp. antibodies (using ELISA confirmed by Western blot) at various sites in Poland. We analysed the frequency of American mink exposure to both parasites, the spatial distribution of seropositive individuals in Poland, and the variability in seropositivity of both parasites over time. We first hypothesized that seropositivity will increase over time, a feat that is connected to patterns of parasite acquisition by non-native invasive mammal species during the colonization of new territories. Secondly, we predicted that the spatial pattern of prevalence in American mink will be related to the spatial pattern in red foxes, but also differ among various locations in Poland. Finally, the third part of our hypothesis claimed that this non-native invasive mammal species serves as a paratenic host for Echinococcus spp. and Toxocara spp. and may play a role in the maintenance and spread of zoonotic parasites on the colonized area.

\section{Methods}

\section{Study Area and Sample Collection}

We collected 1100 American mink individuals between 2006 and 2017. They were trapped at seven study sites: three in eastern Poland (Biebrza National Park-BNP, Narew National Park-NNP, and Vistula River-VR) and four in western Poland (Warta Mouth National ParkWMNP, Drawa National Park-DNP, Gwda River-GR, 


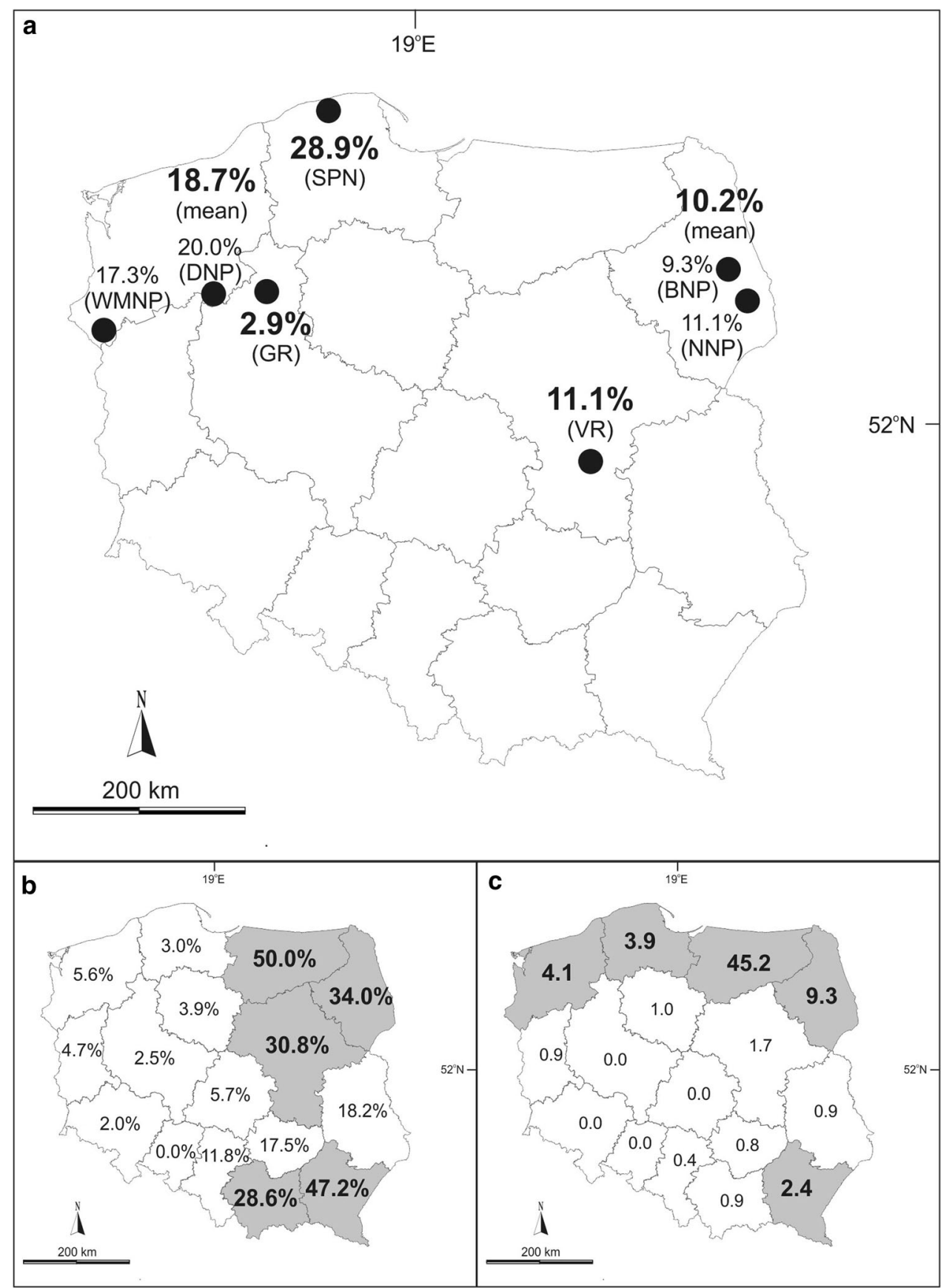

Figure 1. Comparison of the occurrence of echinococcosis in various hosts in Poland: a seroprevalence in the American mink (this study); $\mathbf{b}$ prevalence in the red fox (Karamon et al. 2014); c number of human cases per million inhabitants (data on inhabitant numbers in provinces were taken from the Central Statistical Office of Poland) (Nahorski et al. 2013). Study sites are marked with black dots: WMNP—Warta Mouth National Park, GR—Gwda River, DNP—Drawa National Park, SNP—Słowiński National Park, VR—Vistula River, BNP—Biebrza National Park, NNP - Narew National Park. Seroprevalence of American mink for each studied province is given; in the case of data being made available from two study sites located in one province, the mean value is provided (a). Provinces marked with grey colour indicate places where the highest prevalence of echinococcosis was stated; for red fox above $25 \%$ (b) and for humans above 2 human cases per million inhabitants (c).

and Słowiński National Park-SNP) (see Fig. 1a). In all sites, carcasses were collected during American mink eradication carried out by the staff of national parks or bird conservation organizations as part of several bird conser- vation projects. Thus, based on Resolution No. 22/2006 of the National Ethics Committee for Animal Experiments, no separate approval from the Local Ethics Committee for Animal Experimentation was needed to obtain tissues 
samples from carcasses and conduct the study. Muscle samples (1-5 g) from the diaphragm and hind limbs as well as alimentary tracts were collected during autopsies of American mink and frozen at $-20^{\circ} \mathrm{C}$ until examination.

\section{Parasitological Examination}

Parasitological examination was performed using a standard scraping technique with slight modifications (e.g. Eckert et al. 1984) on 549 randomly selected American mink individuals (50\% of all studied individuals). The alimentary tracts were isolated and examined for the presence of internal parasites, which included, among others, E. multilocularis and Toxocara spp. In brief, each alimentary tract was divided into four parts: stomach, duodenum, small intestine, and large intestine. Each part was then cut longitudinally, and mucosal scrapings were collected. Material from each part of the alimentary tract was examined under a binocular or microscope. Worm burden was determined separately for each tract part.

\section{Preparation of Used Antigens}

Somatic Antigen Echinococcus multilocularis

Metacestodes of E. multilocularis were maintained in Mongolian gerbils (Meriones unguiculatus) by intraperitoneal serial passage of protoscoleces. After careful dissection from the peritoneal cavity, the metacestodes were washed several times in PBS ( $\mathrm{pH}$ 7.2) containing antibiotics and antimycotics and were then pressed through metal mesh screens. After several washing steps, a suspension of protoscoleces free of flocculent tissue debris was obtained. Then, protoscoleces were homogenized in an ice-cold glass (SONOPULS ultrasonic homogenizer HD3100, Bandelin, Germany). The homogenate was centrifuged at $4500 \mathrm{~g}$ for $5 \mathrm{~min}$ at $4^{\circ} \mathrm{C}$, and the supernatant was concentrated in 3000 MWCO Vivaspin tubes (Sartorius, Goettingen, Germany) at $4000 \mathrm{~g}$ for $100 \mathrm{~min}$ at $4^{\circ} \mathrm{C}$. The protein concentration of the larval antigen was measured using the Bradford protein assay (Bio-Rad Laboratories, Munchen, Germany).

\section{Larval Excretory-Secretory Antigen Toxocara canis}

The excretory-secretory antigen of $T$. canis was prepared according to the method of de Savigny (1975). Larvae were cultivated in RPMI 1640 (Sigma-Aldrich, Hamburg,
Germany) medium modified with $20 \mathrm{mM}$ HEPES and Lglutamine, supplemented with penicillin/streptomycin (100 IU, $100 \mu \mathrm{g} / \mathrm{ml}$ ) (Sigma-Aldrich, Hamburg, Germany). Larvae were maintained in sterile $25-\mathrm{ml}$ tissue culture flasks (Falcon, Durham, USA) at a concentration of $10^{3}$ larvae/ml and incubated continually for a long term at $37^{\circ} \mathrm{C}$ under a $5 \% \quad \mathrm{CO}_{2}$ and $95 \%$ atmosphere humidity. The culture medium was replaced at 5-day intervals after assessing the viability of larvae. Starting at the third week, the collected pooled medium (from 3 weeks) was concentrated in 3000 MWCO VIVASPIN tubes (Sartorius, Goettingen, Germany) at $4000 \mathrm{~g}$ for $100 \mathrm{~min}$ at $4^{\circ} \mathrm{C}$. The protein concentration of the larval antigen was measured using the Bradford protein assay (Bio-Rad Laboratories, München, Germany).

\section{Detection of Specific Anti-Echinococcus spp. and Anti-Toxocara spp. Antibodies from Muscle Samples}

Muscles were melted and muscle juice was collected from the samples. The specific detection of anti-Echinococcus spp. and anti-Toxocara spp. antibodies in the muscle juice of American mink-using a somatic antigen from Echinococcus multilocularis protoscoleces and excretorysecretory (E/S) antigen of Toxocara canis larvae-was conducted with an indirect enzyme-linked immunosorbent assay (iELISA) according to Havasiová-Reiterová et al. (1995) with slight modifications. Toxocara canis excretorysecretory antigen (E/S antigen) is highly specific, can detect both $T$. canis and T. cati antibodies, and shows no crossreactivity with other ascarid species (Cuellar et al. 1995; Krucken et al. 2017). Similarly, Echinococcus multilocularis antigen can detect both E. multilocularis and E. granulosis antibodies. The E. multilocularis cestode is principally maintained in sylvatic cycles, and E. granulosus is perpetuated by domestic animals (Thompson 2013). The iELISA was validated with samples from dogs positive with echinococcosis as positive controls $(n=5, E$. multilocularis was confirmed by nested polymerase chain reaction (PCR); Antolová et al. 2009) and toxocarosis ( $n=5$, puppies positive for $T$. canis helminths) and parasite-free dogs $(n=3)$ as negative controls. Anti-dog IgG (Sigma-Aldrich, Hamburg, Germany) was used for the detection of antibodies in American mink. The efficiency of anti-dog IgG conjugate for the detection of mink-specific IgGs was validated by comparison with the multispecies conjugateProtein G Peroxidase from Streptococcus sp. (Sigma-Al- 
drich, Hamburg, Germany). The test was set up after being calibrated with $\mathrm{E} / \mathrm{S}$ antigen (diluted at $1,2,4,10 \mu \mathrm{g} / \mathrm{ml}$ ), muscle juices (undiluted, 1:10, 1:100), and anti-dog IgG conjugate (1:20,000 and 1:30,000). The best signal was chosen to detect anti-parasite antibodies in American mink. Cut-off values (optical density $(\mathrm{OD})=0.500$ for anti-Echinococcus spp. antibodies, $\mathrm{OD}=0.500$ for antiToxocara spp. antibodies) were estimated as the mean absorbance of the negative controls plus three times the standard deviation (SD). We used a generalized linear model (GLM) with Gaussian family to compare OD value of anti-Echinococcus spp. antibodies for four classes of coinfection: individuals negative for Echinococcus spp. (Neg1), individuals negative for Echinococcus spp. but positive for Toxocara spp. (Neg2), individuals positive for Echinococcus spp. but negative for Toxocara spp. (Pos1), and individuals positive for both parasites (mixed infection) (Pos2). A similar GLM was used to analyse OD values of anti-Toxocara spp. antibodies.

Briefly, E. multilocularis and T. canis antigens, diluted to $2 \mu \mathrm{g} / \mathrm{ml}$ carbonate buffer ( $\mathrm{pH} 9.6$ ), were bound to the microtiter plates (Nunc, Thermo Fisher Scientific, Roskilde, Denmark) overnight at $4^{\circ} \mathrm{C}$. After triple-washing of wells with phosphate-buffered saline (PBS, $\mathrm{pH} 7.2$ ) with $0.5 \%$ Tween 20 (PBS-T), non-specific bonds were blocked with $0.5 \%$ skimmed milk PBS after $1 \mathrm{~h}$ of incubation at room temperature. After triple-washing with PBS-T, the muscle juice samples diluted at 1:100 were incubated for $1 \mathrm{~h}$ at $37^{\circ} \mathrm{C}$. All samples were examined in duplicate. After the washings, bound antibodies were detected through incubation for $1 \mathrm{~h}$ at $37^{\circ} \mathrm{C}$ with horseradish peroxidase-conjugated rabbit anti-dog IgG (Sigma-Aldrich, Hamburg, Germany) diluted at 1:20,000. After final washings, the substrate $o$-phenylenediamine (Sigma-Aldrich, Hamburg, Germany) at $0.05 \mathrm{~mol} / \mathrm{l}$ in citrate buffer ( $\mathrm{pH} 4.7)$ with $0.005 \% \mathrm{H}_{2} \mathrm{O}_{2}$ was used to trigger a colour. The reaction was stopped by $1 \mathrm{M} \mathrm{H}_{2} \mathrm{SO}_{4}$ after a 15 -min incubation at room temperature in the dark. The optical density was measured at $492 \mathrm{~nm}$ (Multiskan Reader, Thermo Fisher Scientific, Vantaa, Finland).

To analyse the spatiotemporal variation in seroprevalence, we used a generalized linear model (GLM) with binomial error distribution. The effect of American mink sex, collection site, and year of American mink collection on the presence of both parasites were analysed in the model. All models were computed in the 'Ime4' package in R (R Core Team 2016).

\section{Western Blot}

Samples of 56 American mink, 28 positive for Echinococcus antibodies and 28 positive for Toxocara antibodies by ELISA, were examined by the Western blot technique. Electrophoresis (ELFO-SDS-PAGE) was performed using a Bio-Rad Mini Protein Slab Cell (Bio-Rad Laboratories, CA, USA) on a $12 \%$ SDS-polyacrylamide gel and $4 \%$ stacking gel under reducing conditions (Laemmli 1970). Protoscoleces antigen Echinococcus multilocularis and larval excretory-secretory Toxocara canis antigen were electrophoresed at $150 \mathrm{~V}$ and $90 \mathrm{~mA}$ for $60-70 \mathrm{~min}$ at room temperature. Low molecular weight markers (prestained SDS-PAGE standards, Bio-Rad) were included in each electrophoretic run. Following electrophoresis, proteins were transferred to a nitrocellulose (NC) membrane in Tris-glycine buffer $(\mathrm{pH} 8.8)$ at a constant voltage of $250 \mathrm{~mA}$ and $100 \mathrm{~V}$ for $90 \mathrm{~min}$ using a Bio-Rad Trans-Blot Cell. After blotting, the NC membrane was cut into 2.5mm-wide strips and blocked with $5 \%$ non-fat milk powder in PBS ( $\mathrm{pH} \mathrm{7.2)} \mathrm{for} 60 \mathrm{~min}$ at $37^{\circ} \mathrm{C}$. Meat juices diluted 1:50 with $3 \%$ non-fat milk in PBS were incubated over night at $37^{\circ} \mathrm{C}$. The strips were washed three times with PBS-Tween 20 and reacted with horseradish peroxidaseconjugated anti-dog IgG (Sigma-Aldrich, Hamburg, Germany) in dilution of $1: 500$ for $1 \mathrm{~h}$ at $37^{\circ} \mathrm{C}$ with continuous shaking. Subsequently, the strips were washed three times with PBS-Tween 20, and bands were developed using $0.05 \%$ 4-chloro-1-naphthol in PBS ( $\mathrm{pH} 7.2$ ) and $0.03 \%$ hydrogen peroxide.

Positive control serum was obtained from a dog with confirmed E. multilocularis cysts localized in the liver. Likewise, we obtained Toxocara-positive control serum from a dog that had defecated adult toxocaral larvae after dehelmintization. Negative control serum was obtained from a parasite-free dog. Sera that showed reactions at 8; 16-18; 26-28 kDa bands were considered as Echinococcuspositive. Sera that showed reactions at $35,38,65-78 \mathrm{kDa}$ bands were considered as Toxocara-positive.

\section{Results}

In total, 1100 muscle samples of American mink from seven feral populations were examined for the presence of specific anti-Echinococcus spp. and anti-Toxocara spp. antibodies. Additionally, 50\% of the studied American mink $(n=549)$ were dissected and checked for intestinal 
parasite presence. Of 156 American mink seropositive for echinococcosis and 239 seropositive for toxocarosis, 89 (57\%) and 90 (38\%), respectively, were checked for intestinal parasite presence. Neither Echinococcus spp. nor Toxocara spp. adults were found. Total seroprevalence of Echinococcus spp. and Toxocara spp. in American mink was $14.2 \%$ and $21.7 \%$, respectively (Table 1 ). On average, $6 \%$ of American mink from the seven sites were seropositive for both parasites, which suggests a mixed infection (Fig. 2c). There were no significant differences between OD values for seropositive animals regardless of whether mono- or mixed infections had been demonstrated (Fig. 2a, b; GLM for anti-Echinococcus spp. antibodies: $t=1.71, p=0.087$ and for anti-Toxocara spp. antibodies: $t=-0.21$, $p=0.833$ ).

Seroprevalence varied between the seven study sites (Fig. 3a, b; Tables 1, 2). In detail, the highest Echinococcus spp. seroprevalence was found in SNP (28.9\%) and in DNP $(20.0 \%)$ and for both sites was significantly higher than in GR, BNP, and NNP, where seroprevalence was the lowest: $2.9 \%, 9.3 \%$, and $11.1 \%$, respectively (Tables 1, 2). AntiToxocara spp. antibodies were most prevalent in American mink from VR (72.2\%), GR (65.7\%), and SNP (42.3\%). Seroprevalence was significantly higher in these sites than in WMNP, DNP, BNP, and NNP, where seroprevalence varied between 15.0 and 20.5\% (Tables 1, 2). A comparison of seropositivity proportions in consequent years revealed significant (over three times) increase in Toxocara spp. seropositivity during 12 years of the study (Fig. 3d; Table 2). On the contrary, such dynamics were not ob- served among Echinococcus spp.-seropositive American mink (Fig. 3c; Table 2). Among 156 American mink seropositive for Echinococcus spp., 94 were male (60.2\%) and 62 were female (39.8\%). A similar pattern was observed for Toxocara spp., where from among 239 seropositive animals $144(60.3 \%)$ were male and 95 $(39.7 \%)$ female; however, this relationship was not significant (Fig. 3e, f; Table 2).

The Western blot analysis proved the specificity of IgG antibodies detected in ELISA for both Echinococcus and Toxocara parasites. The examined samples showed specific bands for Echinococcus (8, 16-18, and 26-28 kDa) (Fig. 4a) and Toxocara $(35,38$, and $65-78 \mathrm{kDa}$ ) (Fig. 4b). Additionally, the majority of samples showed bands of 46$65 \mathrm{kDa}$ for Echinococcus and 24 and $120 \mathrm{kDa}$ for Toxocara.

\section{Discussion}

Our study revealed that American mink produce specific anti-Echinococcus spp. and anti-Toxocara spp. antibodies. The specific antibody presence confirms that this non-native invasive mammal species has been exposed to both studied zoonotic parasites in the wild. This- to the best of our knowledge- has never before been confirmed in the literature. Our parasitological investigation of American mink alimentary tracts revealed that neither Echinococcus spp. nor Toxocara spp. adults were found, which may support our hypothesis of American mink being paratenic rather than definitive hosts for either parasite. However, the

Table 1. Seroprevalence of Echinococcus spp. and Toxocara spp. infection in feral American mink from seven study sites in Poland $(n=1100)$.

\begin{tabular}{|c|c|c|c|c|c|c|c|c|c|}
\hline \multirow[t]{2}{*}{ Study site } & \multicolumn{3}{|c|}{ Number of studied animals $(n)$} & \multicolumn{3}{|c|}{$\begin{array}{l}\text { Echinococcus spp. seroprevalence }(\%) \\
\text { ( } n \text { positive in brackets) }\end{array}$} & \multicolumn{3}{|c|}{$\begin{array}{l}\text { Toxocara spp. seroprevalence }(\%) \\
\text { ( } n \text { positive in brackets) }\end{array}$} \\
\hline & Females & Males & Total & Females & Males & Total & Females & Males & Total \\
\hline WMNP & 126 & 232 & 358 & $19.8(25)$ & $15.9(37)$ & 17.3 & $16.7(21)$ & $15.9(37)$ & 16.2 \\
\hline DNP & 30 & 50 & 80 & $23.3(7)$ & $18.0(9)$ & 20.0 & $13.3(4)$ & $16.0(8)$ & 15.0 \\
\hline GR & 18 & 17 & 35 & $0.0(0)$ & $5.9(1)$ & 2.9 & $61.1(11)$ & $70.6(12)$ & 65.7 \\
\hline SNP & 20 & 32 & 52 & $40.0(8)$ & $21.9(7)$ & 28.9 & $55.0(11)$ & $34.4(11)$ & 42.3 \\
\hline VR & 5 & 13 & 18 & $0.0(0)$ & $15.4(2)$ & 11.1 & $40.0(2)$ & $84.6(11)$ & 72.2 \\
\hline BNP & 30 & 78 & 108 & $3.3(1)$ & $11.5(9)$ & 9.3 & $10.0(3)$ & $20.5(16)$ & 17.6 \\
\hline NNP & 210 & 239 & 449 & $10.0(21)$ & $12.1(29)$ & 11.1 & $20.5(43)$ & $20.5(49)$ & 20.5 \\
\hline Total & 439 & 661 & 1100 & $14.1(62)$ & $14.2(94)$ & $14.2(156)$ & $21.6(95)$ & 21.8 & 21.7 (239) \\
\hline
\end{tabular}

WMNP, Warta Mouth National Park; GR, Gwda River; DNP, Drawa National Park; SNP, Słowiński National Park; VR, Vistula River; BNP, Biebrza National Park; NNP, Narew National Park; n, sample size. 
anti-Echinoccus spp.antibodies

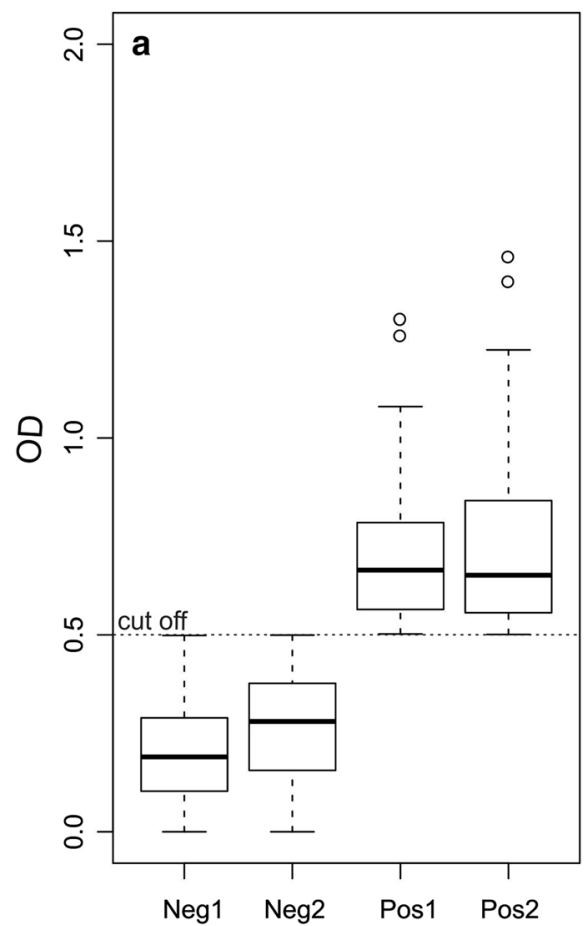

anti-Toxocara spp.antibodies

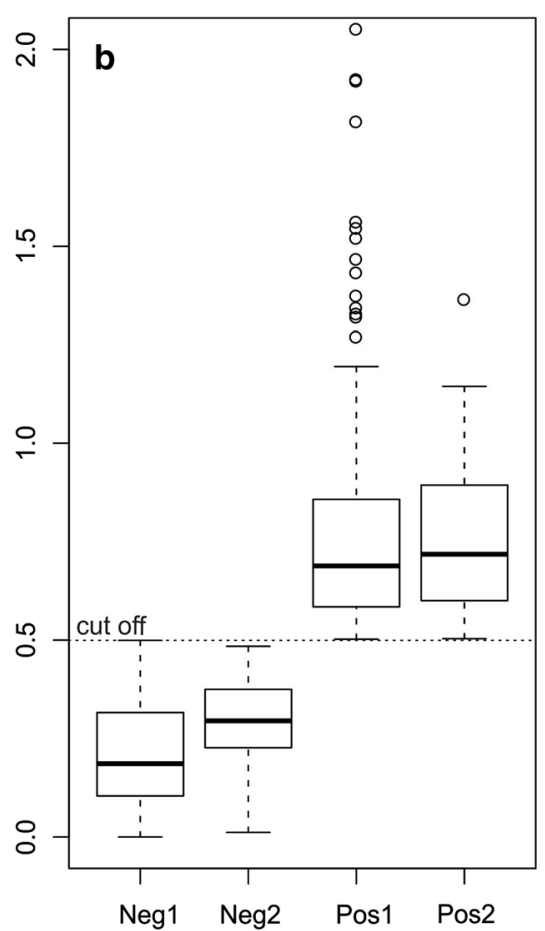

Proportion of specific antibodies

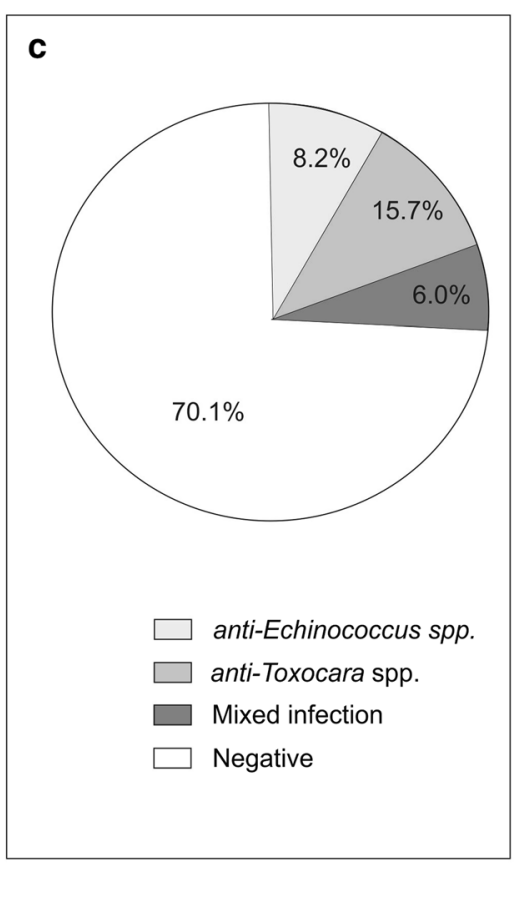

Figure 2. Echinococcus spp. and Toxocara spp. seropositivity of American mink. Optical density (OD) value of ELISA performed for: a individuals negative for Echinococcus spp.-Neg1, individuals negative for Echinococcus spp. but positive for Toxocara spp.-Neg2, individuals positive for Echinococcus spp. but negative for Toxocara spp._-Pos1, individuals positive for both parasites (mixed infection)—Pos2; b individuals negative for Toxocara spp.-Neg1, individuals negative for Toxocara spp. but positive for Echinococcus spp.-Neg2, individuals positive for Toxocara spp. but negative for Echinococcus spp.-Pos1, individuals positive for both parasites (mixed infection)-Pos2; c proportion of American mink seropositive for Echinococcus spp., Toxocara spp., and both parasites (dual infection) in Poland ( $n=1100$ ).

above statement needs to be further supported by more detailed studies, because knowledge about the reservoir of $\mathrm{AE}$ in wildlife is patchy and focuses mainly on red fox (definitive host) infection (Bagrade et al. 2016; Karamon et al. 2014; Miller et al. 2016; Umhang et al. 2016). There is a lack of comprehensive data about the host status of American mink for E. multilocularis. The only one experimental study by Ooi et al. (1992) revealed that after double oral inoculation with 70,000 protoscoleces, no adult tapeworms were recovered from American mink intestines. The authors concluded that American mink cannot serve as a definitive host for E. multilocularis (Ooi et al. 1992). Parasitological studies of wild American mink have not revealed adult E. multilocularis tapeworms in neither Belarus (Shimalov and Shimalov 2001a) nor Poland (KołodziejSobocińska et al. 2018; present study). In addition, adult forms of this tapeworm have not been found in other mustelid species, such as the stone marten (Martes foina), pine marten (Martes martes), European polecat (Mustela putorius), Eurasian badger (Meles meles), weasel (Mustela nivalis), or stoat (Mustela erminea) in Europe (Hurníková et al. 2009; Machnicka-Rowińska et al. 2002; Oksanen et al. 2016; Shimalov and Shimalov 2001b, 2002; Shimalov et al. 2000). Thus, we propose that the American mink serves as a paratenic host for E. multilocularis, since we revealed in the presented study the activation of its specific immune response, despite not finding adult tapeworms during necropsies. In wild definitive hosts, the occurrence of this tapeworm is mainly proved through the conduction of necropsies or the determination of eggs in faeces (Machnicka-Rowińska et al. 2002; Reiterová et al. 2006). Methods for detecting E. multilocularis coproantigen in definitive hosts have also been used (Deplazes and Eckert 1996; Machnicka et al. 2003); unfortunately, confirmation of echinococcosis remains difficult in intermediate/paratenic hosts. In wildlife, AE has only been reported in a few cases: muskrats (Ondrata zibethicus) and coypus (Myocastor coypus) (Miterpáková et al. 2006; Umhang et al. 2013). One study, which revealed E. multilocularis cysts in muskrats with $4.4 \%$ prevalence in Russia (Siberia, Selenga river), 

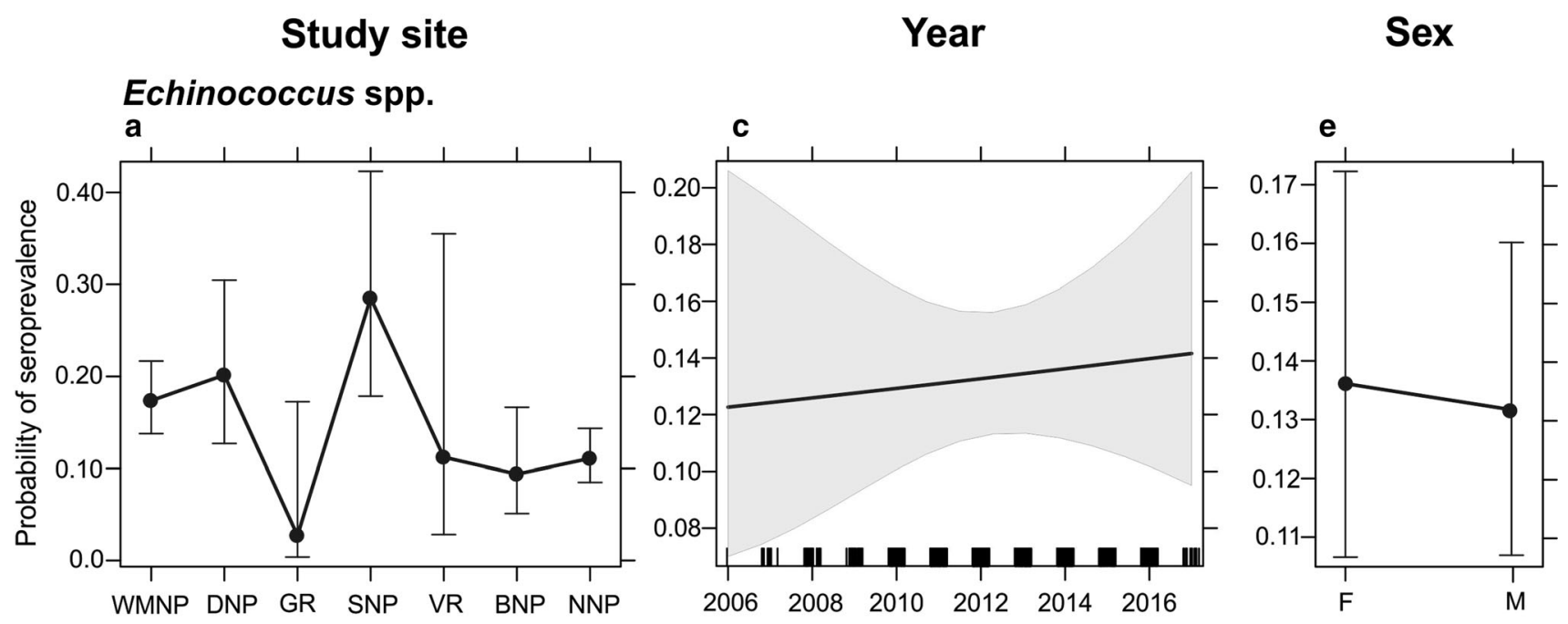

\section{Toxocara spp.}
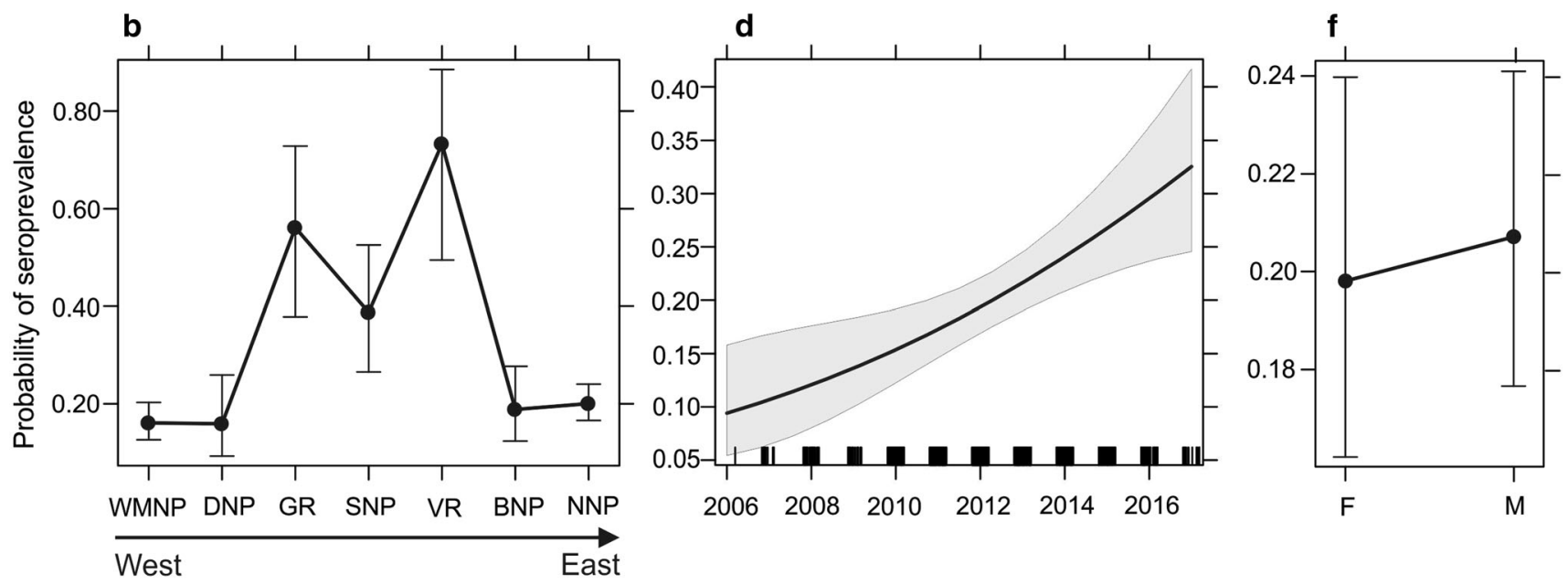

Figure 3. The seroprevalence of Echinococcus spp. and Toxocara spp. in American mink, accompanied by 95\% CIs, in relation to: a, b study site; $\mathbf{c}$, $\mathbf{d}$ year of American mink death; and $\mathbf{e}, \mathbf{f}$ sex as predicted by the generalized linear models (GLM). F-female, $\mathrm{M}-\mathrm{male}$. Rug plots along the $x$ axis show the data distribution.

indicates the American mink as a source of muskrat infection, together with red foxes and domestic dogs (Masur and Fomina 2012).

The second studied parasite, Toxocara spp., can infect a wide range of companion, domestic, and wild animals as both definitive and paratenic hosts via multiple routes of transmission, producing long-lived, tissue-inhabiting larvae and resistant eggs that can survive in the external environment (Holland 2017). A recent experimental study by Klockiewicz et al. (2019a) revealed that American mink may be paratenic hosts for T. canis and T. leonina. In this study, tissue larvae were found in experimentally infected farm American mink; histopathological examinations of parenchymal organs and striated muscles revealed lesions resembling those observed in other paratenic hosts due to toxocarosis (Klockiewicz et al. 2019b). In addition, this infection was irrevocably confirmed by both ELISA and Western blot (Klockiewicz et al. 2019a). Several up-to-date parasitological studies of American mink have been conducted in Belarus (Shimalov and Shimalov 2001a), Spain (Torres et al. 2003), France (Torres et al. 2008), and Poland (Kołodziej-Sobocińska et al. 2018), but neither adult Toxocara spp. specimens nor eggs were detected, as in the present study. Among other mustelid species, pine marten in north-eastern and southern Poland has been found to be infected with Toxocara cati (Borecka et al. 2013; Górski et al. 2006). The difficulties with finding larvae specimens in the tissues of intermediate/paratenic hosts (such as hu- 
Table 2. The analysis of explanatory variables in the generalized linear model (GLM) and their effects on the presence of Echinococcus spp. and Toxocara spp. Significant effects are marked by an asterisk.

\begin{tabular}{|c|c|c|c|c|}
\hline Variables & Estimate & SE & $z$ value & $P$ value \\
\hline \multicolumn{5}{|l|}{ Toxocara } \\
\hline Intercept & -282.64 & 87.25 & -3.24 & $0.00120^{\star *}$ \\
\hline Sex (M) & 0.06 & 0.16 & 0.35 & 0.72382 \\
\hline Year & 0.14 & 0.04 & 3.22 & $0.00128^{\star *}$ \\
\hline WMNP_DNP & -0.01 & 0.35 & -0.04 & 0.97020 \\
\hline WMNP_GR & 1.90 & 0.40 & 4.72 & $0.00000^{* * *}$ \\
\hline WMNP_SNP & 1.20 & 0.32 & 3.75 & $0.00018^{\star * *}$ \\
\hline WMNP_VR & 2.66 & 0.55 & 4.87 & $0.00000^{\star * *}$ \\
\hline WMNP_BNP & 0.19 & 0.29 & 0.66 & 0.51182 \\
\hline WMNP_NNP & 0.27 & 0.19 & 1.44 & 0.14936 \\
\hline GR_DNP & -1.91 & 0.50 & -3.85 & $0.00012^{\star * *}$ \\
\hline SNP_DNP & -1.21 & 0.43 & -2.83 & $0.00465^{\star \star}$ \\
\hline VR_DNP & -2.68 & 0.61 & -4.37 & $0.00001^{* * *}$ \\
\hline BNP_DNP & -0.21 & 0.40 & -0.51 & 0.61019 \\
\hline NNP_DNP & -0.28 & 0.34 & -0.84 & 0.40177 \\
\hline SNP_GR & 0.70 & 0.46 & 1.52 & 0.12784 \\
\hline GR_VR & 0.77 & 0.65 & 1.17 & 0.24133 \\
\hline BNP_GR & 1.71 & 0.46 & 3.68 & $0.00024^{\star * *}$ \\
\hline NNP_GR & 1.63 & 0.39 & 4.16 & $0.00003^{\star * *}$ \\
\hline SNP_VR & 1.47 & 0.60 & 2.45 & $0.01450^{\star}$ \\
\hline BNP_SNP & 1.00 & 0.39 & 2.60 & $0.00944^{\star *}$ \\
\hline NNP_SNP & 0.93 & 0.31 & 3.01 & $0.00261^{\star *}$ \\
\hline BNP_VR & 2.47 & 0.58 & 4.23 & $0.00002^{* * *}$ \\
\hline NNP_VR & 2.39 & 0.54 & 4.43 & $0.00001^{\star * *}$ \\
\hline BNP_NNP & 0.08 & 0.28 & 0.27 & 0.78695 \\
\hline \multicolumn{5}{|l|}{ Echinococcus } \\
\hline Intercept & -31.83 & 93.65 & -0.34 & 0.73400 \\
\hline Sex $(M)$ & -0.04 & 0.18 & -0.21 & 0.83270 \\
\hline Year & 0.02 & 0.05 & 0.32 & 0.74640 \\
\hline WMNP_DNP & 0.18 & 0.31 & 0.58 & 0.55990 \\
\hline WMNP_GR & -2.02 & 1.03 & -1.95 & 0.05130 \\
\hline WMNP_SNP & 0.64 & 0.34 & 1.88 & 0.06010 \\
\hline WMNP_VR & -0.51 & 0.76 & -0.67 & 0.50480 \\
\hline WMNP_BNP & -0.71 & 0.36 & -1.96 & 0.05050 \\
\hline WMNP_NNP & -0.52 & 0.21 & -2.53 & $0.01140^{\star}$ \\
\hline DNP_GR & -2.20 & 1.07 & -2.06 & $0.03910^{\star}$ \\
\hline DNP_SNP & 0.46 & 0.42 & 1.09 & 0.27670 \\
\hline DNP_VR & -0.69 & 0.80 & -0.86 & 0.38800 \\
\hline DNP_BNP & -0.89 & 0.43 & -2.05 & $0.04056^{\star}$ \\
\hline DNP_NNP & -0.70 & 0.32 & -2.21 & $0.02734^{\star}$ \\
\hline GR_SNP & 2.66 & 1.06 & 2.50 & $0.01249^{\star}$ \\
\hline GR_VR & 1.51 & 1.27 & 1.19 & 0.23620 \\
\hline GR_BNP & 1.31 & 1.08 & 1.21 & 0.22640 \\
\hline GR_NNP & 1.49 & 1.03 & 1.45 & 0.14850 \\
\hline
\end{tabular}

Table 2. continued

\begin{tabular}{lclll}
\hline Variables & Estimate & SE & $z$ value & $P$ value \\
\hline SNP_VR & -1.15 & 0.81 & -1.41 & 0.15734 \\
SNP_BNP & -1.35 & 0.46 & -2.93 & $0.00336^{\text {** }}$ \\
SNP_NNP & -1.16 & 0.34 & -3.38 & $0.00072^{\star * *}$ \\
VR_BNP & -0.20 & 0.82 & -0.24 & 0.80900 \\
VR_NNP & -0.01 & 0.77 & -0.02 & 0.98600 \\
BNP_NNP & 0.18 & 0.37 & 0.50 & 0.61592 \\
\hline
\end{tabular}

WMNP, Warta Mouth National Park; GR, Gwda River; DNP, Drawa National Park; SNP, Słowiński National Park; VR, Vistula River; BNP, Biebrza National Park; NNP, Narew National Park.

${ }^{\star} P>0.05 ;{ }^{\star \star} P>0.01 ;{ }^{\star \star *} P>0.001$

mans) have led to the development of serological tests for use in toxocarosis diagnostics (Dziemian et al. 2008; Fillaux and Magnaval 2013). Used on rodent hosts, these methods deduced a $14.2 \% \quad T$. canis seroprevalence and showed ELISA to be more sensitive than PCR for detecting infection with the parasite (Krucken et al. 2017). Studies using immunodiagnostic methods have been carried out worldwide (Krucken et al. 2017; Li et al. 2017; Lassen et al. 2016; Klockiewicz et al. 2019a). Serological analysis also allows the easy detection of mixed infections in hosts. Our research showed that, on average, $6 \%$ of American mink are seropositive for both Echinococcus and Toxocara parasites.

As the American mink hosts many more parasite species (Hurníková et al. 2016; Kołodziej-Sobocińska et al. 2018; Torres et al. 2003, 2008), it likely plays a role in maintaining and transporting infectious agents during the colonization of new territories. The pronounced increase in Toxocara spp. seropositivity proportion over time is consistent with the pattern of parasite acquisition by non-native American mink in the course of the colonization of Poland (Kołodziej-Sobocińska et al. 2018). We did not observe such patterns for Echinococcus spp. seropositivity in American mink. This may be connected with an increase in mink density over time (Brzeziński et al. 2019), which results in American mink inhabiting areas closer to human development, this increasing the contact rate of American mink with dogs and cats (Felis catus). Dogs and cats are more involved in Toxocara spp. than in Echinococcus spp. transmission, which is mainly transmitted by wild carnivores, i.e. red fox or raccoon dog. In addition, we found great variation in the proportion of seropositive American mink in space; the highest seroprevalence of toxocarosis occurred in sites located in central Poland, while very low seroprevalence was seen in sites located in eastern and 


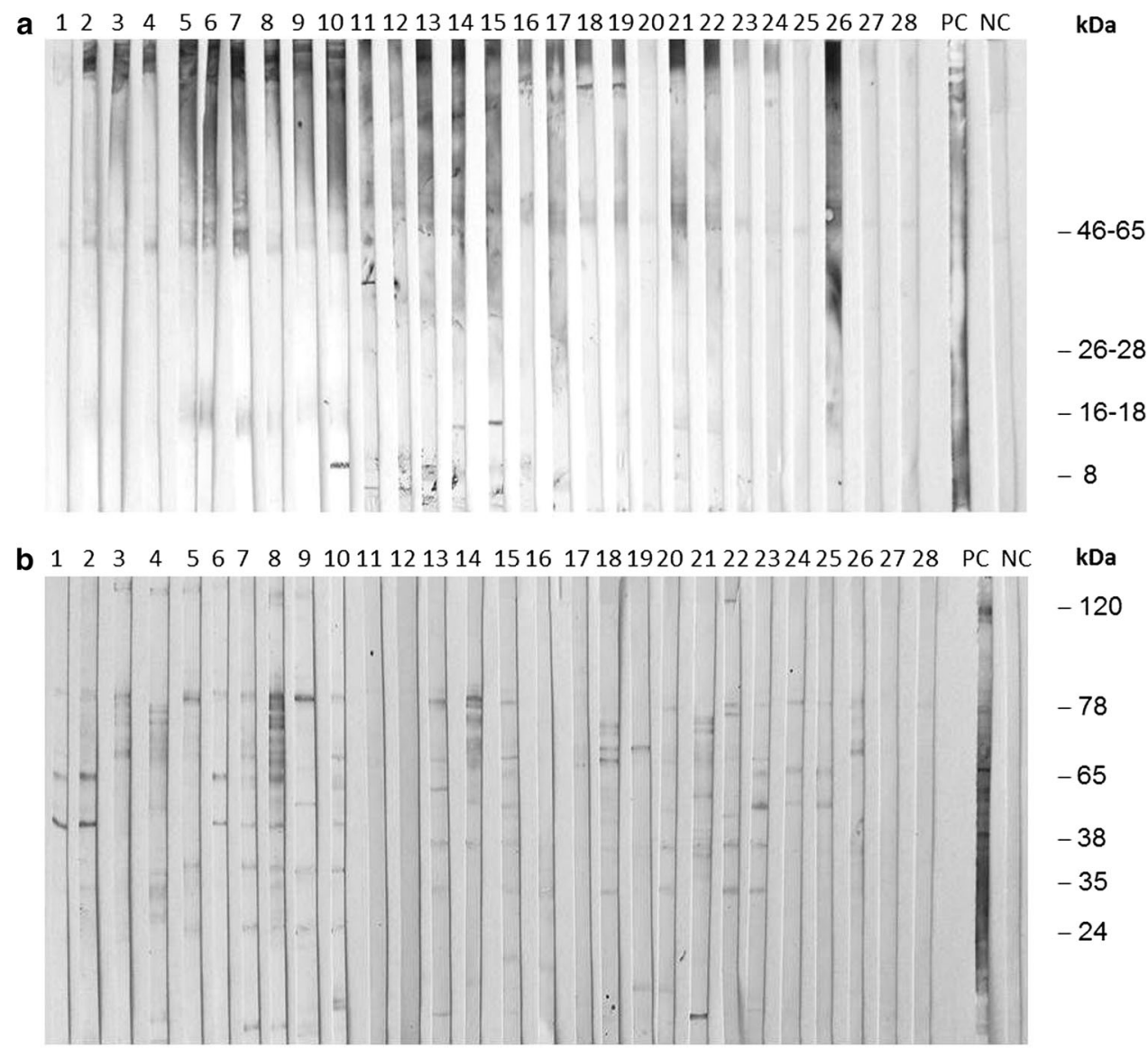

Figure 4. Western blot analysis of: a Echinococcus-specific IgG antibodies in selected American mink samples. The lines represent: 1-28selected American mink samples ELISA-positive for Echinococcus, PC-positive E. multilocularis control dog serum, NC-negative control dog serum. b Toxocara-specific IgG antibodies in selected American mink samples. The lines represent: 1-28-selected American mink samples ELISA-positive for Toxocara, PC-positive T. canis control dog serum, NC-negative control dog serum.

western Poland. This finding is difficult to explain; however, areas with a high prevalence of infected animals present a constant infection pressure for definitive and paratenic hosts. An opposite explanation may suggest that the abundance of Toxocara spp. in the environment had increased during the last years of the study. Further analyses of both spatial and temporal patterns may highlight the mechanisms of the circulation of both parasites in the environment.

Unravelling the role of non-native species in the epidemiology of pathogens is important to more sufficiently manage diseases. Such a role (in the maintenance and spread of pathogens) becomes even more crucial when the infectious agents can instigate serious diseases in humans (Duscher et al. 2017; Hurníková et al. 2016; Laurimaa et al. 2016). The American mink cannot transmit both parasites to humans by shedding parasite eggs, as it seems to be a paratenic host. However, American mink can be eaten by other predators who act as definitive hosts for Echinococcus spp. and/or Toxocara spp. including the wolf, Eurasian lynx, red fox, raccoon dog, and pets such as dogs and cats (Bryan et al. 2006; Errington 1937; Odden et al. 2006; Sepúlveda et al. 2014). As a result, high American mink densities in some areas (Bartoszewicz and Zalewski 2003) may sustain high infection risks in ecosystems.

In the case of E. multilocularis, it is thought that human $\mathrm{AE}$ is mainly present in areas with high densities of infected red foxes (Nahorski et al. 2013; Schweiger et al. 2007). We also hypothesized that the frequency of Echinococcus spp. seropositive in American mink should be higher in areas with a high infection prevalence of red fox. However, these data are not consistent in northern and north-western Poland, which have some of the lowest infection rates seen in red foxes (Karamon et al. 2014) (Fig. 1b), though relatively high seroprevalence in American mink as well as high numbers of confirmed human $\mathrm{AE}$ cases (Nahorski et al. 2013) (Fig. 1a, c). Similarly, nonnative raccoon dogs have been found infected with $E$. 
multilocularis in north-western Poland, suggesting that wild species other that red fox may influence the occurrence of human cases (Machnicka-Rowińska et al. 2002; Karamon et al. 2016). Even if a species serves as a paratenic host, as American mink does, it may also serve as a prey item for definitive hosts like red fox or raccoon dog. In this way, paratenic hosts may enhance the probability of disease transmission (Wobeser 2006). This causes the circulation of the parasite in the wild, and as a result, the parasite may be maintained at high abundances in the environment and also affect infection levels in humans. More studies are needed to investigate the source of human infection in these areas, including the role of American mink and other non-native species.

\section{CONCLUSIONS}

To conclude, our study shows that the non-native invasive American mink is a species exposed to two serious zoonotic parasite genera-Echinococcus and Toxocara. Relatively high seropositivity of American mink in some feral populations indicates that the species may have a role in the maintenance of these parasites in wildlife. As the American mink may serve as a paratenic host, it can be an important link in the transmission routes of these parasites. Spatial distribution and high American mink densities occurring on colonized areas result in higher seropositivity of American mink over time and space; as a result, this may cause the host to maintain higher levels of infection risk for both wild and domestic definitive hosts, thus increasing the risk of human infection through contact with the environment contaminated with Echinococcus spp. and/or Toxocara spp. eggs.

\section{ACKNOWLEDGEMENTS}

The study was supported by Project No. DEC-2012/05/B/ NZ8/01247 funded by the National Science Centre, Poland, and by Grant VEGA No. 2/0056/19. The biological material for the study was collected under the EU Life + project Polish Important Bird Areas No. LIFE09 NAT/PL/000263. We would like to thank Ewelina Hapunik, Eva Nováková, Eugeniusz Bujko, and Dariusz Chilecki for technical assistance and Tomasz Diserens and Anita Michalak for correcting the English in the manuscript.

\section{Compliance with Ethical Standards}

CONFLICT OF INTEREST The authors declare that they have no competing interests.

\section{OPEn ACCESS}

This article is licensed under a Creative Commons Attribution 4.0 International License, which permits use, sharing, adaptation, distribution and reproduction in any medium or format, as long as you give appropriate credit to the original author(s) and the source, provide a link to the Creative Commons licence, and indicate if changes were made. The images or other third party material in this article are included in the article's Creative Commons licence, unless indicated otherwise in a credit line to the material. If material is not included in the article's Creative Commons licence and your intended use is not permitted by statutory regulation or exceeds the permitted use, you will need to obtain permission directly from the copyright holder. To view a copy of this licence, visit http://creativec ommons.org/licenses/by/4.0/.

\section{REFERENCES}

Antolová D, Reiterová K, Miterpáková M, Dinkel A, Dubinsky P (2009) The first finding of Echinococcus multilocularis in dogs in Slovakia: an emerging risk for spreading of infection. Zoonoses Public Health 56(2):53-58. https://doi.org/10.1111/j.18632378.2008.01154.x

Antolová D, Miterpáková M, Radonak J, Hudackova D, Szilagyiova M, Zacek M (2014) Alveolar echinococcosis in a highly endemic area of northern Slovakia between 2000 and 2013 . Eurosurveillance 19(34):13-20

Bagrade G, Deksne G, Ozolina Z, Howlett SJ, Interisano M, Casulli A, Pozio E (2016) Echinococcus multilocularis in foxes and raccoon dogs: an increasing concern for Baltic countries. Parasites \& Vectors 9:615. https://doi.org/10.1186/s13071-0161891-9

Bartoszewicz M, Zalewski A (2003) American mink, Mustela vison diet and predation on waterfowl in the Slonsk Reserve, western Poland. Folia Zoologica 52(3):225-238

Beck R, Gaspar A, Mihaljevic Z, Marinculic A, Stojcevic D, Brstilo M (2005) Evaluation of ELISA for detection of Trichinella antibodies in muscle juice samples of naturally infected pigs. Veterinary Parasitology 132(1-2):91-95. https://doi.org/10.1016/ j.vetpar.2005.05.034

Bonesi L, Palazon S (2007) The American mink in Europe: status, impacts, and control. Biological Conservation 134(4):470-483. https://doi.org/10.1016/j.biocon.2006.09.006

Bonesi L, Harrington LA, Maran T, Sidorovich VE, Macdonald DW (2006) Demography of three populations of American mink Mustela vison in Europe. Mammal Review 36:98-106 
Borecka A, Gawor J, Zieba F (2013) A survey of intestinal helminths in wild carnivores from the Tatra National Park, southern Poland. Annales Parasitology 59(4):169-172

Bryan HM, Darimont CT, Reimchen TE, Paquet PC (2006) Early ontogenetic diet in gray wolves, Canis lupus, of coastal British Columbia. The Canadian Field-Naturalist 120(1):61-66. https:// doi.org/10.22621/cfn.v120i1.247

Brzeziński M, Chibowska P, Zalewski A, Borowik T, Komar E (2018a) Water vole Arvicola amphibius population under the impact of the American mink Neovison vison: Are small midfield ponds safe refuges against this invasive predator? Mammalian Biology 93:182-188. https://doi.org/10.1016/j.mambio.2018.06. 002

Brzeziński M, Ignatiuk P, Żmihorski M, Zalewski A (2018b) An invasive predator affects habitat use by native prey: American mink and water vole co-existence in riparian habitats. Journal of Zoology 304:109-116. https://doi.org/10.1111/jzo.12500

Brzeziński M, Żmihorski M, Zarzycka A, Zalewski A (2019) Expansion and population dynamics of a non-native invasive species: the 40-year history of American mink colonisation of Poland. Biological Invasions 21:531-545. https://doi.org/ 10.1007/s10530-018-1844-7

Brzeziński M, Żmihorski M, Zalewski A (2020) The expansion wave of an invasive predator leaves declining waterbird populations behind. Diversity and Distributions 26:138-150. https:// doi.org/10.1111/ddi.13003

Carolus H, Muzarabani KC, Hammoud C, Schols R, Volckaert FA, Barson M, Huyse T (2019) A cascade of biological invasions and parasite spillback in man-made Lake Kariba. Science of the Total Environment 659:1283-1292

Chen J, Liu Q, Liu GH, Zheng WB, Hong SJ, Sugiyama H, Zhu XQ, Elsheikha HM (2018) Toxocariasis: a silent threat with a progressive public health impact. Infectious Diseases of Poverty 7:59. https://doi.org/10.1186/s40249-018-0437-0

Cuellar C, Fenoy S, Guillen JL (1995) Cross-reactions of sera from Toxascaris leonina and Ascaris suum infected mice with Toxocara canis, Toxascaris leonina and Ascaris suum antigens. International Journal for Parasitology 25(6):731-739. https://doi.org/ 10.1016/0020-7519(94)00187-s

Deplazes P, Eckert J (1996) Diagnosis of the Echinococcus multilocularis infection in final hosts. Applied Parasitology 37(4):245252

Duscher T, Hodžić A, Glawischnig W, Duscher GG (2017) The raccoon dog (Nyctereutes procyonoides) and the raccoon (Procyon lotor) - their role and impact of maintaining and transmitting zoonotic diseases in Austria. Central Europe. Parasitology Research 116(4):1411-1416. https://doi.org/ 10.1007/s00436-017-5405-2

Dziemian E, Żarnowska H, Kołodziej-Sobocińska M, Machnicka B (2008) Determination of the relative avidity of the specific IgG antibodies in human toxocariasis. Parasite Immunology 30(3):187-190. https://doi.org/10.1111/j.1365-3024.2007. 01010.x

Eckert J, Deplazes P (2004) Biological, epidemiological, and clinical aspects of echinococcosis, a zoonosis of increasing concern. Clinical Microbiology Review 17:107-135

Eckert J, Gemmel MA, Soulsby EJL, Matyas Z (1984) Guidelines for sureillance, prevention and control of echinococcosis/hydatidosis, Geneva: World Health Organisation

Errington PL (1937) Food habits of Iowa red foxes during a drought summer. Ecology 18(1):53-61. https://doi.org/10.2307/ 1932702
Fillaux J, Magnaval JF (2013) Laboratory diagnosis of human toxocariasis. Veterinary Parasitology 193(4):327-336. https:// doi.org/10.1016/j.vetpar.2012.12.028

Gottsteina B, Frey CF, Campbell-Palmer Pizzi R, Barlow A, Hentrich B, Posautz A, Ryser-Degiorgis MP (2014) Immunoblotting for the serodiagnosis of alveolar echinococcosis in alive and dead Eurasian beavers (Castor fiber). Veterinary Parasitology 205(1-2):113-118. https://doi.org/10.1016/j.vetpar.2014.06.017

Górski P, Zalewski A, Łakomy M (2006) Parasites of carnivorous mammals in Białowieza Primeval Forest. Wiadomości Parazytologiczne 52(1):49-53

Havasiová-Reiterová K, Tomašovicová O, Dubinský P (1995) Effect of various doses of infective Toxocara canis and Toxocara cati eggs on the humoral response and distribution of larvae in mice. Parasitology Research 81(1):13-17. https://doi.org/ 10.1007/bf00932411

Holland CV (2017) Knowledge gaps in the epidemiology of Toxocara: the enigma remains. Parasitology 144(1):81-94. https://doi.org/10.1017/s0031182015001407

Hurníková Z, Kołodziej-Sobocińska M, Dvorožňáková E, Niemczynowicz A, Zalewski A (2016) An invasive species as an additional parasite reservoir: Trichinella in introduced American mink (Neovison vison). Veterinary Parasitology 231:106-109. https://doi.org/10.1016/j.vetpar.2016.06.010

Hurníková Z, Miterpáková M, Chovancova B (2009) The important zoonoses in the protected areas of the Tatra National Park (TANAP). Wiadomości Parazytologiczne 55(4):395-398

Jędrzejewska B, Sidorovich VE, Pikulik MM, Jędrzejewski W (2001) Feeding habits of the otter and the American mink in Białowieża Primeval Forest (Poland) compared to other Eurasian populations. Ecography 24:165-180

Jorgensen P, van der Heiden M, Kern P, Schoneberg I, Krause G, Alpers K (2008) Underreporting of human alveolar echinococcosis, Germany. Emerging Infectious Diseases 14(6):935-937

Karamon J, Kochanowski M, Sroka J, Cencek T, Różycki M, Chmurzyńska E, Bilska-Zając E (2014) The prevalence of Echinococcus multilocularis in red foxes in Poland-current results (2009-2013). Parasitology Research 113(1):317-322. https://doi.org/10.1007/s00436-013-3657-z

Karamon J, Samorek-Pieróg M, Moskwa B, Różycki M, BilskaZając E, Zdybel J, Włodarczyk M (2016) Intestinal helminths of raccoon dogs (Nyctereutes procyonoides) and red foxes (Vulpes vulpes) from the Augustów Primeval Forest (north-eastern Poland). Journal of Veterinary Research 60:273-277

Kauhala K (1996) Distributional history of the American mink (Mustela vison) in Finland with special reference to the trends in otter (Lutra lutra) populations. Annales Zoologici Fennici 33:283-291

Kelly DW, Paterson RA, Townsend CR, Poulin R, Tompkins DM (2009) Parasite spillback: A neglected concept in invasion ecology? Ecology 90(8):2047-2056. https://doi.org/10.1890/081085.1

Kern P, Bardonnet K, Renner E, Auer H, Pawlowski Z, Ammann RW, Vuitton DA (2003) European echinococcosis registry: human alveolar echinococcosis, Europe, 1982-2000. Emerging Infectious Diseases 9(3):343-349

Klockiewicz M, Jakubowski T, Sobczak-Filipiak M, Bartosik J, Długosz E (2019a) Experimental infection with T. canis and T. leonina in farm mink (Neovison vison). Journal of Veterinary Research 63:197-203. https://doi.org/10.2478/jvetres-2019-0033 
Klockiewicz M, Sobczak-Filipiak M, Jakubowski T, Długosz E (2019b) Histopathological lesions by experimental Toxocara canis and Toxascaris leonina infections in farm mink (Neovison vison). Journal of Veterinary Research 63:205-214. https://doi. org/10.2478/jvetres-2019-0034

Kolarova L, Mateju J, Hrdy J, Kolarova H, Hozakova L, Zampachova V, Auer H, Stejskal F (2015) Human alveolar echinococcosis, Czech Republic, 2007-2014. Emerging Infectious Diseases 21(12):2263-2265. https://doi.org/10.3201/eid2112. 150743

Kołodziej-Sobocińska M, Brzeziński M, Niemczynowicz A, Zalewski A (2018) High parasite infection level in non-native invasive species: It is just a matter of time. Ecography 41:12831294. https://doi.org/10.1111/ecog.03362

Krucken J, Blumke J, Maaz D, Demeler J, Ramunke S, Antolová D, Schaper R, von Samson-Himmelstjerna G (2017) Small rodents as paratenic or intermediate hosts of carnivore parasites in Berlin. Germany. PLoS One 12(3):e0172829. https://doi.org/ 10.1371/journal.pone.0172829

Laemmli UK (1970) Cleavage of structural proteins during the assembly of the head of the bacteriophage T4. Nature 277:680685. https://doi.org/10.1038/227680a0

Lassen B, Janson M, Viltrop A, Neare K, Hutt P, Golovljova I, Tummeleht L, Jokelainen P (2016) Serological evidence of exposure to globally relevant zoonotic parasites in the Estonian population. PLoS One 11:e0164142. https://doi.org/10.1371/ journal.pone.0164142

Laurimaa L, Süld K, Davison J, Moks E, Valdmann H, Saarma U (2016) Alien species and their zoonotic parasites in native and introduced ranges: The raccoon dog example. Veterinary Parasitology 219:24-33. https://doi.org/10.1016/j.vetpar.2016.01.020

Li K, Zhang LH, Zhang H, Lei ZX, Luo HQ, Mehmood K, Shahzad M, Lan YF, Wang M, Li JK (2017) Epidemiological investigation and risk factors of Echinococcus granulosus in yaks (Bos grunniens), Tibetan pigs and Tibetans on Qinghai Tibetan plateau. Acta Tropica 173:147-152. https://doi.org/10.1016/ j.actatropica.2017.06.019

Machnicka-Rowińska B, Rocki B, Dziemian E, Kołodziej-Sobocińska M (2002) Raccoon dog (Nyctereutes procyonoides) - the new host of Echinococcus multilocularis in Poland. Wiadomości Parazytologiczne 48(1):65-68

Machnicka B, Dziemian E, Rocki B, Kołodziej-Sobocińska M (2003) Detection of Echinococcus multilocularis antigens in faeces by ELISA. Parasitology Research 91(6):491-496. https:// doi.org/10.1007/s00436-003-0994-3

Martínez-Rondán FJ, de Ruiz Ybáñez MR, Tizzani P, LópezBeceiro AM, Fidalgo LE, Martínez-Carrasco C (2017) The American mink (Neovison vison) is a competent host for native European parasites. Veterinary Parasitology 247(Supplement C):93-99. https://doi.org/10.1016/j.vetpar.2017.10.004

Masur OE, Fomina AS (2012) Revelation of Echinococcus multuilocularis (Leukart 1856) in the muskrat (Ondrata zibethicus) of the delta of the Selenga river (Russia). Russian Journal of Biological Invasions 5(3):38-43

Miller AL, Olsson GE, Sollenberg S, Skarin M, Wahlstrom H, Hoglund J (2016) Support for targeted sampling of red fox (Vulpes vulpes) feces in Sweden: a method to improve the probability of finding Echinococcus multilocularis. Parasites \& Vectors 9:613. https://doi.org/10.1186/s13071-016-1897-3

Miterpáková M, Antolová D, Ševčíková Z, Stanko M, Dinkel A, Gašpar V, Dubinský P (2006) Echinococcus multilocularis in musk rat (Ondatra zibethicus): the first finding of the parasite in naturally infected rodent in the Slovak Republic. Helminthologia 43(2):76-80. https://doi.org/10.2478/s11687-006-0015-z

Møller LN, Petersen E, Gamble HR, Kapel CMO (2005) Comparison of two antigens for demonstration of Trichinella spp. antibodies in blood and muscle fluid of foxes, pigs and wild boars. Veterinary Parasitology 132(1-2):81-84. https://doi.org/ 10.1016/j.vetpar.2005.05.032

Nahorski WL, Knap JP, Pawłowski ZS, Krawczyk M, Polański J, Stefaniak J, Patkowski W, Szostakowska B, Pietkiewicz H, Grzeszczuk A, Felczak-Korzybska I, Gołąb E, Wnukowska N, Paul M, Kacprzak E, Sokolewicz-Bobrowska E, NiścigorskaOlsen J, Czyrznikowska A, Chomicz L, Cielecka D, Myjak P (2013) Human alveolar echinococcosis in Poland: 1990-2011. PLoS Neglected Tropical Diseases 7:e1986. https://doi.org/ 10.1371/journal.pntd.0001986

Nentwig W, Kuhnel E, Bacher S (2010) A generic impact-scoring system applied to alien mammals in Europe. Conservation Biology 24(1):302-311. https://doi.org/10.1111/j.15231739.2009.01289.x

Niemczynowicz A, Świętochowski P, Brzeziński M, Zalewski A (2017) Non-native predator control increases the nesting success of birds: American mink preying on wader nests. Biological Conservation 212(Part A):86-95. https://doi.org/10.1016/j.bioc on.2017.05.032

Nöckler K, Serrano FJ, Boireau P, Kapel CMO, Pozio E (2005) Experimental studies in pigs on Trichinella detection in different diagnostic matrices. Veterinary Parasitology 132(1-2):85-90. https://doi.org/10.1016/j.vetpar.2005.05.033

Odden J, Linnell JDC, Andersen R (2006) Diet of Eurasian lynx, $\operatorname{Lynx} \operatorname{lyn} x$, in the boreal forest of southeastern Norway: the relative importance of livestock and hares at low roe deer density. European Journal of Wildlife Research 52(4):237-244. https://doi.org/10.1007/s10344-006-0052-4

Oksanen A, Siles-Lucas M, Karamon J, Possenti A, Conraths FJ, Romig T, Wysocki P, Mannocci A, Mipatrini D, La Torre G, Boufana B, Casulli A (2016) The geographical distribution and prevalence of Echinococcus multilocularis in animals in the European Union and adjacent countries: a systematic review and meta-analysis. Parasites \& Vectors 9(1):519

Ooi HK, Inaba C, Kamiya M (1992) Experimental evaluation of mink and Apodemus speciosus in the Echinococcus multilocularis life-cycle in Hokkaido, Japan. Journal of Wildlife Diseases 28(3):472-473

Overgaauw PAM, Nederland V (1997) Aspects of Toxocara epidemiology: human toxocarosis. Critical Reviews in Microbiology 23(3):215-231. https://doi.org/10.3109/10408419709115137

Pagnozzi D, Addis MF, Biosa G, Roggio AM, Tedde V, Mariconti M, Tamarozzi F, Meroni V, Masu G, Masala G, Brunetti E, Uzzau S (2016) Diagnostic accuracy of antigen 5-based ELISAs for human cystic echinococcosis. PLoS Neglected Tropical Diseases 10:e004585. https://doi.org/10.1371/journal.pntd. 0004585

R Core Team (2016) R: A language and environment for statistical computing. R Foundation for Statistical Computing, Vienna, Austria. http://www.R-project.org/

Reiterová K, Dziemian E, Miterpáková M, Antolová D, KołodziejSobocińska M, Machnicka B, Dubinsky P (2006) Occurrence of Echinococcus multilocularis in red foxes from the Carpathian regions of Slovakia and Poland. Acta Parasitologica 51(2):107110. https://doi.org/10.2478/s11686-006-0016-6

Schweiger A, Ammann RW, Candinas D, Clavien P-A, Eckert J, Gottstein B, Halkic N, Muellhaupt B, Prinz BM, Reichen J, Tarr 
PE, Torgerson PR, Deplazes P (2007) Human alveolar echinococcosis after fox population increase, Switzerland. Emerging Infectious Diseases 13(6):878-882. https://doi.org/ 10.3201/eid1306.061074

Sepúlveda MA, Singer RS, Silva-Rodriguez EA, Eguren A, Stowhas P, Pelican K (2014) Invasive American mink: linking pathogen risk between domestic and endangered carnivores. Ecohealth 11(3):409-419. https://doi.org/10.1007/s10393-014-0917-z

Shimalov VV, Shimalov VT (2001a) Helminth fauna of the American mink (Mustela vison Schreber, 1777) in Belorussian Polesie. Parasitology Research 87(10):886-887

Shimalov VV, Shimalov VT (2001b) Helminth fauna of the stoat (Mustela erminea Linnaeus, 1758) and the weasel (M. nivalis Linnaeus, 1758) in Belorussian Polesie. Parasitology Research 87(8):680-681 https://doi.org/10.1007/s004360000373

Shimalov VV, Shimalov VT (2002) Helminth fauna of the European polecat (Mustela putorius Linnaeus, 1758) in Belorussian Polesie. Parasitology Research 88(3):259-260. https://doi.org/ 10.1007/s00436-001-0521-3

Shimalov VV, Shimalov VT, Shimalov AV (2000) Helminth fauna of otter (Lutra lutra Linnaeus, 1758) in Belorussian Polesie. Parasitology Research 86(6):528. https://doi.org/10.1007/ s004360050708

Sidorovich VE (2000) The on-going decline of riparian mustelids (European mink, Mustela lutreola, polecat, Mustela putorius, and stoat, Mustela erminea) in eastern Europe: a review of the results to date and an hypothesis. Mustelids in a modern world. Management and conservation aspects of small carnivore: human interactions, Ed. H.I. Griffiths. Backhuys Publishers, Leiden, The Netherlands pp 295-317

Sidorovich VE, Polozov AG, Zalewski A (2010) Food niche variation of European and American mink during the American mink invasion in north-eastern Belarus. Biological Invasions 12:2207-2217. https://doi.org/10.1007/s10530-009-9631-0

Strauss A, White A, Boots M (2012) Invading with biological weapons: the importance of disease-mediated invasions. Functional Ecology 26(6):1249-1261

Thompson RCA (2013) Parasite zoonoses and wildlife: one health, spillover and human activity. International Journal for Parasitology 43(12-13):1079-1088. https://doi.org/10.1016/j.ijpara.2013.06.007
Torres J, Manas S, Palazon S, Cena JC, Miquel J, Feliu C (2003) Helminth parasites of Mustela lutreola (Linnaeus, 1761) and M. vison Schreber, 1777 in Spain. Acta Parasitologica 48(1):55-59

Torres J, Miquel J, Fournier P, Fournier-Chambrillon, Liberge M, Fons R, Feliu C (2008) Helminth communities of the autochthonous mustelids Mustela lutreola and M. putorius and the introduced Mustela vison in south-western France. Journal of Helminthology 82(4):349-355. https://doi.org/10.1017/ s0022149x08046920

Umhang G, Comte S, Hormaz V, Boucher J-M, Raton V, Favier S, Raoul F, Giraudoux P, Combes B, Boué F (2016) Retrospective analyses of fox feces by real-time PCR to identify new endemic areas of Echinococcus multilocularis in France. Parasitology Research 115(11):4437-4441. https://doi.org/10.1007/s00436-0165220-1

Umhang G, Richomme C, Boucher JM, Guedon G, Boue F (2013) Nutrias and Muskrats as bioindicators for the presence of Echinococcus multilocularis in new endemic areas. Veterinary Parasitology 197(1-2):283-287. https://doi.org/10.1016/j.vetpar.2013.05.003

Wobeser GA (2006) Essentials of Disease in Wild Animals, USA: Blackwell Publishing

Vitousek PM, Dantonio CM, Loope LL, Westbrooks R (1996) Biological invasions as global environmental change. American Scientist 84(5):468-478

Zalewski A, Bartoszewicz M (2012) Phenotypic variation of an alien species in a new environment: the body size and diet of American mink over time and at local and continental scales. Biological Journal of the Linnean Society 105(3):681-693. https:// doi.org/10.1111/j.1095-8312.2011.01811.x

Zalewski A, Michalska-Parda A, Bartoszewicz M, Kozakiewicz M, Brzeziński M (2010) Multiple introductions determine the genetic structure of an invasive species population: American mink Neovison vison in Poland. Biological Conservation 143(6):1355-1363. https://doi.org/10.1016/j.biocon.2010.03.009

Zalewski A, Piertney SB, Zalewska H, Lambin X (2009) Landscape barriers reduce gene flow in an invasive carnivore: geographical and local genetic structure of American mink in Scotland. Molecular Ecology 18(8):1601-1615. https://doi.org/10.1111/ j.1365-294X.2009.04131 